\section{Life Before Birth: Consensus in Medical Ethics}

Kenneth Boyd, Brendan Callaghan SJ and Edward Shotter, 168 pages, Holy Trinity Church, Marylebone Road, London NW1 4DU, £6.95, SPCK, 1986

This book is a result of study into the ethics of abortion and the treatment of infertility. It is aimed at Church leaders, students of theology, members of the medical and allied professions and at policy-makers and legislators and the general audience. It is very logically divided into two parts; one dealing with abortion or destruction of life, the other with the treatment of infertility or the making of life. Each part is then subdivided into three sections, namely, Public statement, Discussion and Comment. The Public statement in each part outlines the significant statements made by Parliament and by medical, professional and ecclesiastical bodies on abortion and infertility, paying particular attention to the Report of the Warnock Committee.

The first sections of both parts of the book are clear and thorough and for anyone not familiar with the Acts, Bills, statements and reports concerning abortion or infertility is a good source of reference. It clarifies without doubt, the attitude of the Churches to the various reports produced by medical and related bodies and by Government instigated reports and Bills. The three Christian Churches represented, the Roman Catholic, the Anglican and the Church of Scotland, find themselves in basic agreement on the subjects of abortion and infertility. The Anglican Church would appear to have a more reasonable and human approach than the other two Churches. The Roman Catholic Church is more inwardlooking, remaining rigid in its stand on ethics and morals although individual freedom of conscience is recognised but not encouraged.

The second sections of both parts of the book represent the views of a selected panel consisting of twelve individuals, six members of the medical profession including one medical student, three chaplains - one from the Roman Catholic Church, one from the Anglican Church and one from the Scottish Churches - a nurse who also represents the Church of Scotland, a radiographer who also represents the Anglican Church and a teacher who is a Roman Catholic. The discussion panel is disappointing in its composition. There are obvious gaps. For example, there are no social workers or health visitors, no special support nurses who have direct contact with individuals and families needing help, no genetic counsellors or scientists; and the views of the young seem to be represented by the single medical student. Most of all, it lacked the views of individuals directly concerned with the main issues, the women and girls who have sought or obtained termination of pregnancy and the couples who suffer the anguish of infertility. Without them, the discussion is just another academic exercise without real substance, and despite efforts made by the gynaecologist and the general practitioner, in both parts of the book, the discussion is based on limited scientific knowledge. The discussion on abortion was more informed than the one on infertility, which is a more complex subject offering a number of alternatives. However, without the views of those who have actually experienced abortion and infertility, the discussion remains shallow and biased. Surprisingly, no one raises the topic of individual responsibilities towards these two vital issues.

In the final section the comments reflect the point of view of the Churches, largely dominated by the
Roman Catholic stand. On reading these comments - on infertility in particular, one is left with the feeling that the Churches have a monopoly on ethics and morals and that the scientist is the bad guy. While the Roman Catholic Church is logical in the light of its teachings on ethics and morals, in my opinion, it does not hold the monopoly on truth, and in relation to advances in medicine tends to be out of touch with day-to-day reality: since on the other side of each moral debate there are individual human beings in need of help for whom we must try to do the best we can, whatever our beliefs. Although there is much that one can agree ando identify with in this book there is also. much that causes anger and frustration because of the lack of compassion and understanding. This book simply reaffirms the traditional stand of the Churches and widens the gap between their position and current medical practice.

MARIE E FERGUSON-SMITH Principal Scientific Officer, Department of Clinical Cytogenetics, Addenbrooke's Hospital, Level 2, Hills Rd, Cambridge CB2 $2 Q Q$

\section{Ethics and Regulation of Clinical Research}

Robert J Levine, 2nd edition, 452 pages, $£ 38$, Baltimore-Munich, Urban and Schwarzenberg, 1986

'This book is a survey of the ethical and legal duties of clinical researchers' states the author.

It is substantially based on the reports of the (USA) President's Commission for the Study of Ethical Problems in Medicine and Biomedical and Behavioural Research, and the National Commission for the Protection for Human Subjects of Biomedical and Behavioural Research. The author has 
served on both these commissions, and more, including 'such agencies as the National Institutes of Health, the Commission on the Federal Drug Approval Process as well as various other international, national, State, Yale University agencies, committees, working groups, task forces and advisory boards'. The author continues to tell us about himself in impressive detail and 'particularly those things that have been most influential in shaping my relevant perspective and intuitions'.

Dr Levine (currently Professor of Medicine at Yale University) has been (or is) an academic physician (internal medicine), a laboratory researcher in biochemical pharmacology, a research subject and a clinical investigator of: patients having rare and common diseases, normal volunteers, children, students, elderly persons, mentally retarded persons and their families, and two dead fetuses.

'One constant in my professional life has been a fondness for words. In the organisations I take seriously, the positions to which I tend to be elected or appointed are secretary or editor. I once declined a nomination for presidency of a national research organisation in favour of . . . See page xvii if you want the answer. The author wonders if he will ever 'possess simultaneously sufficient arrogance and energy to write an autobiography'. I have no doubt of the answer to this question, and I shall buy a copy.

If a reader is not, at this stage, softened up, he should turn to the bibliography of 754 items of which 55 are by Dr Levine (as sole author in about 50).

The author makes no attempt to be international on this international subject. The book is, for practical purposes, entirely American, though here and there a non-American reference peeps out, for example Bradford Hill on the ethics of controlled trials. A Dr Percival of England makes an appearance recommending peer review in 1803, but 'not much more was said about peer review for 150 years'; an example of the British syndrome, perhaps, "have an idea but do not follow it up'? The USA has indeed been a leader in the debate on, and the analysis of, ethical issues in human research, and I suspect there is no other country that can even approach it in the sheer volume of discussion and reports, many of high quality.

The book begins with a chapter on Basic Concepts and Definitions which includes a section on Unacceptable Terminology in which the terms 'therapeutic research' and 'nontherapeutic research' are condemned because the distinction confuses and is 'illogical'. For example when patients in a randomised controlled trial receive a placebo it cannot be said to have potential therapeutic value for them. Because of such difficulties the President's Commission abandoned these terms, seeking to improve matters by confining the word 'research' to 'something other than therapeutic' investigations. 'More cumbersome language is employed by the Commission to convey the meaning intended most commonly by those who had used the expression "therapeutic research".' Out of the frying pan into the fire! I cannot think that restriction of the word research in this way can be generally acceptable; using it to mean only some research must cause confusion.

Dr Levine includes the word 'experimentation' as 'unacceptable terminology' because it is 'commonly and incorrectly used as a synonym for research'. This is indeed true, but the better course might be to employ this useful word correctly and educate others to do so. If we are to abandon useful words because they are often misused, where will this lead us?

We are surely entitled to hope for better than this from a writer who states that 'words are perhaps my most important professional tools', although he adds that they 'are also among my favourite toys' and, coyly admits that he loves puns, twists, double meanings and the like. He tries, he says, to exclude these from his professional writings but, he confides, 'occasionally, I fail'. Readers should not be put off by all this, and by the author's somewhat imperious approach, for example: 'Avoidable breaches of confidentiality should be treated as punishable offences'; 'Investigators should be advised to consult the IRB (ethics committee) to assure themselves that they are not going to commit any punishable offence'.

If ethical review of research is to provide reassurance to both subjects and the public, then surely it must be mandatory that all research be reviewed. It can hardly be satisfactory that the decision that review is required be left to the investigator. In the USA it seems that opponents of 'federally mandated' ethical review have claimed that mandatory review would be unconstitutional, at least for research that is not funded by the federal government.

Much research presents only trivial ethical issues and Dr Levine heads one section IRBs (ethics committees) Invest Too Much Time and Energy in Doing Unimportant Things, and The IRB is Not a Police Force. The chapter on IRBs is $\mathbf{4 0}$ pages. Dr Levine examines the cost of review activities, finds it too high, and proposes that only research 'in which there is a high probability of violating one or more fundamental ethical principles', and research to evaluate therapeutic manoeuvres, should be subject to ethical review. Where subjects are 'reasonably autonomous adults' review may be confined to competence of investigators and to the scientific design. There should be a 'presumption of trust' until there is evidence to the contrary. The author recognises that he is proposing a radical change, and he supports it by advocating severe penalties for specified offences. 'Those who are caught committing these offences will be punished in certain specified ways. This is how we deal with murder, rape, arson and embezzlement'. But he considers the criminal law will apply only in extreme cases and that academic or professional procedures will be generally adequate. In other wordso back to self-regulation, supported b severe penalties for transgression. H thus rejects the proposition that the history of unethical human research (of which he has given examples) has created a general presumption of mistrust. Whatever one's immediate reaction, this author must be taken seriously.

There is much in this book, for example USA Federal Regulations and law, that is irrelevant to the UK, but there is a great deal of discussion that will exercise the minds of investigators and members of research ethics committees here, for example 18 pages on Deception, and 58 on Informed Consent. There are frank passages on Public Concerns with Justice which summarise famous scandals: the Tuskegee Syphilis Study (untreated patients with syphilis), the Willowbrook Studies (natural history of infective hepatitis), the Jewish Chronic Disease Hospital Study (injection of live cancer cells into patients who were not told the nature of the cells because 'this would frighten them unnecessarily'), and the San Antonio Contraceptive Study (randomised, double-blind, placebo-controlled, in which patients were not told that a placebo would be used).

One of the most admirable qualities that I recognise in the USA is exemplified in this book, ie total 
frankness about defects and the intention to learn from them. The idiosyncrasies of the author will irritate some, but all who read or merely dip into this book will be informed and their wits will be sharpened. I did not find 'puns, twists or double-entendres', but I hope they are there waiting for me when I return to the book, as I shall.

All the major areas of concern indicated by the title are discussed. The book should be available in the library of all institutions that appoint research ethics committees. Too often ethics committee members are unaware that there is available rigorous discussion of issues that at present most of us deal with by good intentions informed by intuition.

D R LAURENCE Emeritus Professor of Pharmacology and Therapeutics, University College, London and the Middlesex Hospital Medical School, London

\section{Human}

\section{Experimentation. A Guided Step into the Unknown}

William A Silverman, 204 pages, New York, £15, Oxford Medical Publications, 1986

Dr Silverman has written a book which links the methodology of clinical science with social and ethical concerns; a book which is consequently directed at a broad audience both within and outside the medical profession. In describing the basic design of clinical experiments and the problems that are inherent in investigation in medicine, Silverman also makes an eloquent plea for increased discipline in a profession which is entrusted with enormous power over the well-being and lives of patients. This plea is not restricted to clinical investigators but directed also to practising physicians, to students, and indeed to society at large.

The book discusses, in detail, the architecture, components and problems of the randomised controlled clinical trial which is certainly the most powerful method of clinical investigation available today, especially in evaluation of therapy. Despite the title of the book little mention is made of laboratory experimentation or the investigation of physiology and pathology (often misleadingly called 'non-therapeutic' investigation). Consequently certain problems in human experimentation are not discussed - one thinks, for example, of the question of whether healthy incompetent persons can be exposed to any form of experimental risk. In addition, the failure of the public (and also the profession) to discriminate between research in which the subject has no interest (other than pecuniary or altruistic) and that in which the subject may gain (for example by receiving a new or different treatment) is not mentioned.

Silverman's philosophy regarding ethical issues is encapsulated in a comment from Rutstein that it may be accepted as a maxim that a poorly or improperly designed study involving human subjects is by definition unethical'.

This approach to ethical concerns is utilitarian to the point of pragmatism. For example, he answers concerns about random allocation to different treatments by pointing out that they arise from a paradox. On the one hand is the concern that one group will not receive a new and potentially valuable treatment while on the other is the concern that the experimental group will be exposed to an un-proven and potentially dangerous new treatment. In practice since it is equally as likely for a new therapy to be beneficial as not, then neither of these concerns has any basis. Similarly, in making a plea for increased openness in the discussion of scientific investigation Silverman relies not upon the rights of individuals to be informed but upon the needs for an increasingly scientific medicine to be objective and open to criticism.

Silverman is a paediatrician and he makes frequent reference to his experience in newborn paediatrics and to the problems in evaluating the cause of blindness in premature infants. It is somewhat of a surprise, therefore, that the section dealing with surrogate consent or permission from children and infants is short and does not really do justice to the problem. There is a brief discussion of a proposal to change the procedure for obtaining consent from adults to a plan that Silverman calls 'informed surveillance'. In this format a patient's personal doctor is responsible for providing information to the patient who then gives a written affirmation that he/she has 'no objections to proceeding'. Such a proposal would be entirely dependent on the nature of the relationship between the individual doctor and patient and could conceivably result in varying loss of autonomy by the patient. It certainly deserves a greater discussion than has been provided in this book.

However, these criticisms are minor when placed in the context of the remainder of the book which is detailed but easily readable. An unusual characteristic is the placement of anecdotes, comments and quotations throughout the book, rather like illustrations; these verbal illustrations often take the place of footnotes and make Human Experimentation a book which is easily picked up and browsed through. Despite this ease of browsing I would strongly recommend that the book be read cover to cover by anyone who is likely to be performing, reading about, or the subject of, clinical experimentation. In particular the book should be recommended to those in the earliest stages of learning the discipline of medicine and the discipline of science, that is to medical students and residents.

JOHN WATTS

Professor of Paediatrics, McMaster University, Hamilton, Ontario

\section{Mental Health Services - Law and Practice}

Larry Gostin, 800 pages, £85, London, Shaw and Sons, 1986

The 1983 Mental Health Act created a new framework for the treatment of the mentally ill. It married welfarist principles with their emphasis of the proper treatment of the patient, with principles of legalism which seek to protect the human rights of the patient. The result is not only a set of new rules governing admission, treatment and discharge but also a new institutional structure with key roles for the approved social worker at one end of the process, and the Mental Health Act Commission at the other. As legal director of MIND the author of this text was closely involved in the development of the consensus which led to the legislation. This shows in the text: it is not just a comprehensive account of both the common law and legislation affecting the mentally ill, it is written with an evident feel for the subject matter. It is a looseleaf text but unlike many of its kind, it is not simply a dry exposition of the sections of the statute. Rather, it sets the law in its historical and social context producing as a result, a very readable text. To the reviewer, a lawyer, it presented an accurate and 